\title{
Evaluation Study of Surface Characteristics for the Compact Yarns Manufactured on Different Compacting Systems
}

Narkhedkar $\mathbf{R N}^{*}$ and Shinkar $\mathbf{R}$

DKTE Society's Textile \& Engineering Institute, Ichalkaranji, India

\begin{abstract}
The compact yarns are dominating the yarn market today, with the passing time the demand for the compact yarns will go on increasing. The compact spun yarns mainly find applications in the apparel and fashion industry. From the Techno-commercial perspective, these applications demand the yarns to possess excellent surface characteristics such as fine appearance, less friction, high lustre, superior abrasion resistance, and certain moisture relations. This work is an industrial case study carried out to assess the surface characteristics of the compact yarns. The necessary attributes important from the end-use perspective were identified and stressed upon. Here, the yarns manufactured on different compact spinning systems i.e. System R, System S \& System D were compared. The Yarns manufactured on all the three systems were found to possess peculiar and different properties. 'System R' yarn excels in terms of comfort due to the high value of short hairs, low friction etc. whereas 'System D' yarn can be said to possess excellent process ability particulars due to its high abrasion resistance, low hairiness values. The yarns are thus characterised accordingly.
\end{abstract}

Keywords: Compact spinning; Surface characteristics; Yarn lustre; Yarn moisture; Yarn friction; Yarn surface profile

\section{Introduction}

Surface attributes of a textile product i.e. yarn in this case, have crucial importance as they matter the most for an end product, especially in conjunction with the apparel textiles. To quote an example when a customer goes to a boutique to buy an outfit, what does he look for? Importantly the Appearance and the Feel of the fabric. These surface attributes are harnessed in the apparels from the fabrics used. Study of surface properties of a fabric starts from its basic component i.e. yarn.

The surface characteristics of the fabrics and thus the end products/ garments have a significant correlation with the yarn attributes. A yarn with harsher feel results into a harsher fabric, as studied by Ajayi and Elder, the yarn friction and fabric friction have a very good correlation, this influences the feel of the fabric. The comfort properties of a fabric comprising of the thermal conductivity, air permeability, wicking behaviour and moisture vapour transmission are directly affected by the yarn structure $[1,2]$. The pilling behaviour and abrasion resistance of fabrics depend on the yarn surface profile [3]. Along with this, the relationship between the yarn and fabric properties has been long established.

System $\mathrm{R}$ is based on the perforated drum principle, whereas System $S$ and System D come as an attachment for which the ring frame drafting system has to be modified (Figure 1).

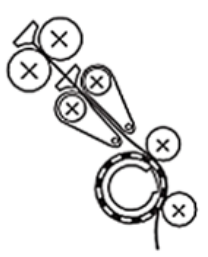

System R

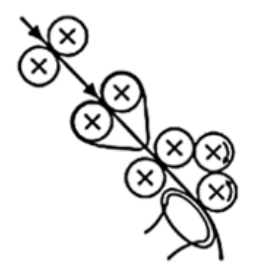

System S

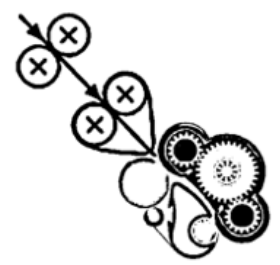

System D
Figure 1: Principles of compact spinning systems.

\section{Materials and Methods}

$100 \%$ cotton material is used for manufacturing the yarn samples. The raw material used to manufacture the experimental samples is generally ideal to spin yarns within the count range of $50 \mathrm{~s} \mathrm{Ne}$. The details of the fibres used for spinning are as shown in following Table 1.

The Design of Experiment comprises of a completely randomized design (CRD) with a $2 \times 3$ matrix. Three compact spinning technologies that were available in the mill under the same roof were considered that include System R, System S and System D. Two hanks, of $0.9 \mathrm{Ne}$ and $1.1 \mathrm{Ne}$ were used to spin the yarn on all of these systems. The parameters set on the spinning frames when spinning the yarns are as given Table 2 [4].

Statistical selection of samples was practised to avoid biasing in the results; special care was taken so as the sample is a representative of the

\begin{tabular}{|c|c|c|}
\hline S. No. & Particulars & Description \\
\hline $\mathbf{1 .}$ & Cotton variety & $\mathrm{MECH}$ \\
\hline $\mathbf{2 .}$ & UHML (upper half mean length) & $31.05 \mathrm{~mm}$ \\
\hline $\mathbf{3 .}$ & Micronaire value & $4.09 \mu \mathrm{gm} / \mathrm{inch}$ \\
\hline $\mathbf{4 .}$ & Uniformity index & 83.80 \\
\hline $\mathbf{5 .}$ & Tenacity & $30.5 \mathrm{cN} / \mathrm{tex}$ \\
\hline $\mathbf{6 .}$ & Trash & $2.8 \%$ \\
\hline $\mathbf{7 .}$ & Afis Neps & 95 \\
\hline $\mathbf{9 .}$ & Moisture content & $6.5 \%$ \\
\hline
\end{tabular}

Table 1: Fibre Properties used for spinning

*Corresponding author: Narkhedkar RN, Assistant Professor, Department of Textile, DKTE Society's Textile \& Engineering Institute, Ichalkaranji, India, Tel: +919850623592; E-mail: 0441office@msbte.com

Received August 06, 2018; Accepted August 18, 2018; Published August 29, 2018

Citation: Narkhedkar RN, Shinkar R (2018) Evaluation Study of Surface Characteristics for the Compact Yarns Manufactured on Different Compacting Systems. J Textile Sci Eng 8: 373. doi: 10.4172/2165-8064.1000373

Copyright: (C) 2018 Narkhedkar RN, et al. This is an open-access article distributed under the terms of the Creative Commons Attribution License, which permits unrestricted use, distribution, and reproduction in any medium, provided the original author and source are credited. 
entire bulk. In bobbin and between bobbin variation were considered, the yarns were sent on to the winding machines for winding and the wound yarns were taken for testing that are free from objectionable faults [5-8].

\section{Yarn testing}

All the tests performed on the materials were as per the standard norms for testing available as shown in the Table 3. The minimum no of samples were calculated by statistical assistance. The results obtained from testing were statistically analysed by the two way ANOVA Technique with $5 \%$ level of significance so as to consider the results reliable Table $3[9,10]$.

An objective analysis ideal for comparative study was taken to calculate the yarn lustre, where the indirect values for the reflectance of the greige yarn, were obtained on the CCM machine by taking the standard white plate as the reference. The Microscopic images were taken on a projection microscope with 75x Magnification [11-13].

\section{Results and Discussion}

\section{Surface irregularities}

This study shows the irregularities on the surface of the yarn. Which indicates the variation on the yarn surface? This study of yarn consists of the following sub studies:

Mass variation: During the yarn formation the yarn mass per unit length is decided by the number of fibre in yarn cross section. The number of fibre in yarn cross section is decided by the various factors. This variation in the number of fibres in yarn cross section decides the yarn unevenness (Figure 2).

As reflected by above Figure 2 a similar trend was followed for both the short term and long term ( 1 metre) mass variation. It can be seen that technology plays a crucial role on the irregularities and imperfections. It can be observed that System S exhibits the lowest variation followed by System D and then System R. The inferior performance of System D

\begin{tabular}{|c|c|c|c|c|c|c|c|}
\hline Sr. No. & Particulars & \multicolumn{2}{|c|}{ System R } & \multicolumn{2}{|c|}{ System S } & \multicolumn{2}{|c|}{ System D } \\
\hline 1. & Drafting system & \multicolumn{2}{|c|}{ Drum type $4 / 3$} & \multicolumn{2}{|c|}{ apron type $4 / 3$} & \multicolumn{2}{|c|}{ apron type $4 / 3$} \\
\hline 2. & Traveller type & \multicolumn{2}{|c|}{$8 / 0$} & \multicolumn{2}{|c|}{$11 / 0$} & \multicolumn{2}{|c|}{$11 / 0$} \\
\hline 3. & Ring Diameter & \multicolumn{2}{|c|}{$38 \mathrm{~mm}$} & \multicolumn{2}{|c|}{$38 \mathrm{~mm}$} & \multicolumn{2}{|c|}{$38 \mathrm{~mm}$} \\
\hline 4. & Roller Hardness & \multicolumn{2}{|c|}{$68 / 63 / 83$} & \multicolumn{2}{|c|}{$68 / 63 / 83$} & \multicolumn{2}{|c|}{$68 / 65 / 83$} \\
\hline 5. & Spindle Speed & \multicolumn{2}{|c|}{19000} & \multicolumn{2}{|c|}{18200} & \multicolumn{2}{|c|}{18200} \\
\hline 6. & Twist Multiplier & \multicolumn{2}{|c|}{3.95} & \multicolumn{2}{|c|}{3.95} & \multicolumn{2}{|c|}{3.95} \\
\hline 7. & Count & \multicolumn{2}{|c|}{50} & \multicolumn{2}{|c|}{50} & \multicolumn{2}{|c|}{50} \\
\hline 8. & Break Draft & \multicolumn{2}{|c|}{1.18} & \multicolumn{2}{|c|}{1.18} & \multicolumn{2}{|c|}{1.18} \\
\hline 9. & Main Draft & \multicolumn{2}{|c|}{42.37} & \multicolumn{2}{|c|}{42.37} & \multicolumn{2}{|c|}{42.37} \\
\hline 10. & Suction pressure & \multicolumn{2}{|c|}{$2686 \mathrm{~Pa}$} & \multicolumn{2}{|c|}{$3300 \mathrm{~Pa}$} & \multicolumn{2}{|c|}{$2377 \mathrm{~Pa}$} \\
\hline 11 & Feed Hank & 0.9 & 1.1 & 0.9 & 1.1 & 0.9 & 1.1 \\
\hline
\end{tabular}

Table 2: Process particulars for ring spinning machine.

\begin{tabular}{|c|c|c|}
\hline Sr. no. & Yarn Properties & Standards \\
\hline 1 & Practice for sampling yarns & D2258 \\
\hline 2 & Count and its CV (\%) & D1907 \\
\hline 3 & Tensile properties and their CV (\%) & D2256 \\
\hline 4 & Elongation and its CV (\%) & D2256 \\
\hline 5 & Unevenness $\%$ & D1425 \\
\hline 6 & Hairiness (Zweigle) & D5647 \\
\hline 7 & Yarn Friction (yarn to metal) & D3108 \\
\hline
\end{tabular}

Table 3: Testing standards for manufactured yarns. compared to System S can be attributed to the fibre accumulation over the aprons observed during the manufacturing.

It can be seen that, when spinning with a finer feed hank two of the systems show increase in the Unevenness, as the break draft was same for both the roving used as feed hank, the $1.1 \mathrm{Ne}$ thus receives higher twist compared to $0.9 \mathrm{Ne}$ and may have been a cause of the resistance in the fibre flow. This result was observed with a significant difference.

\section{Surface integrity}

The integration of the fibres with the yarn body especially of the fibres on the surface will govern the surface integrity properties of the compact yarns. The surface integrity governs the yarn characteristics like hairiness, friction, abrasion resistance which are directly related to the surface. It affect other properties such as yarn lustre, dye ability etc., as a whole.

Hairiness: Yarn hairiness is the number of fibres protruding out of the yarn body. The fibres which are not properly embedded in to the yarn structure protrude out of the yarn body. The Figure 3 shows the trend of hairiness of different yarn samples.

Short hairs observed are significantly higher in case of System R, followed by System $S$ and then System D, this may be a peculiarity of the yarns produced on the System R, this can be understood better by looking at the microscopic images of the yarns, where the loops that are seen on the system $\mathrm{R}$ yarn body maybe a potential cause for the higher obtained value of hairiness. Both the systems with Groove tube principle show lower short hairs compared to System R. The System D has the lowest value of short hairs, this can be attributed to the higher suction length available in the system. However, The System D shows the lowest S3 value (long hairs) compared to the other two systems. Whereas the results of System $S$ \& System R, are seen to be interacting, the superiority of the System D can be attributed to the higher suction length or the higher length of the compacting zone associated with the system.

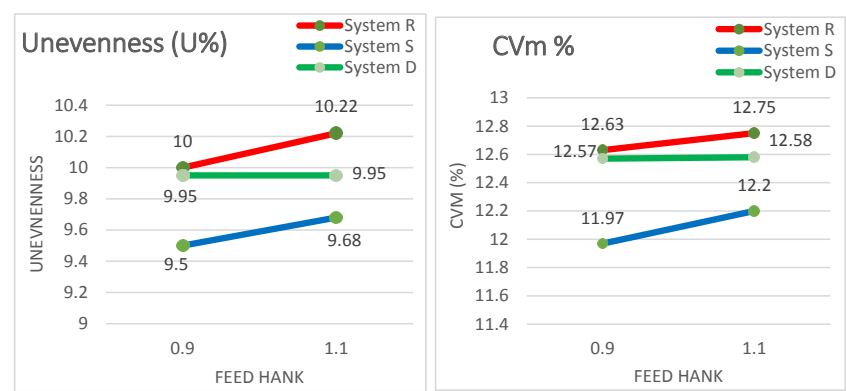

Figure 2: Unevenness and $\mathrm{CVm} \%$
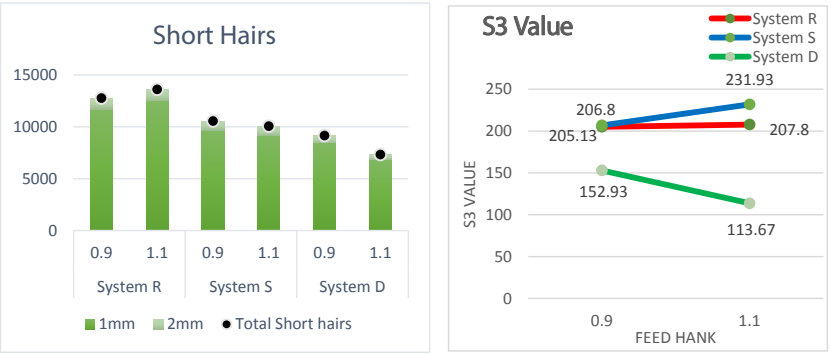

Figure 3: Yarn hairiness. 
Yarn friction and abrasion resistance: The frictional property of the yarn helps in showing the abrasion behaviour of the yarn. The friction and abrasion resistance of the different yarns is as shown in the following Figure 4.

The results obtained for yarn friction reveal an interesting fact about the yarns manufactured on the System R, These yarns exhibit lesser friction when compared to the yarns manufactured on other two, and this can be the effect of the higher number of short hairs or the resultant loops present on the yarn surface which enhance the smoothness of the yarn by facilitating localized movement of fibres thus reducing the friction in the yarn.

The System D yarn exhibits comparatively much higher abrasion resistance value compared to both the systems i.e. System $\mathrm{R}$ and System D which show interaction for abrasion resistance value, this can be attributed to the lesser hairiness and higher yarn density of the yarn produced on the System $S$ which makes the yarn manufactured superior in terms of abrasion resistance.

The Design of the compacting zone plays a very crucial role in the integrity of fibres. Higher number of short hairs was observed in System R, and the long hairs were same as the other systems. This
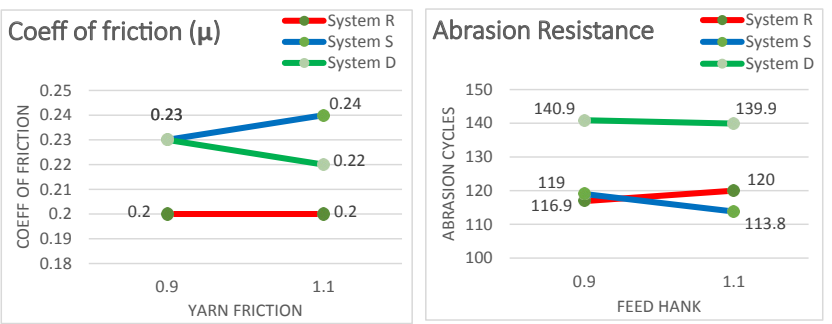

Figure 4: Yarn coefficient of friction $(\mu)$ and Abrasion Resistance.

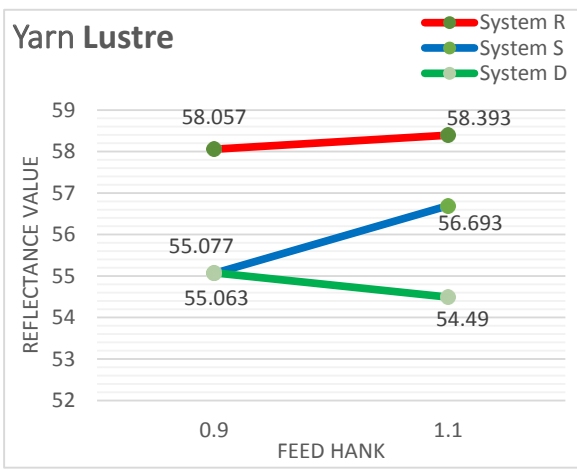

Figure 5: Lustre of different yarn samples.

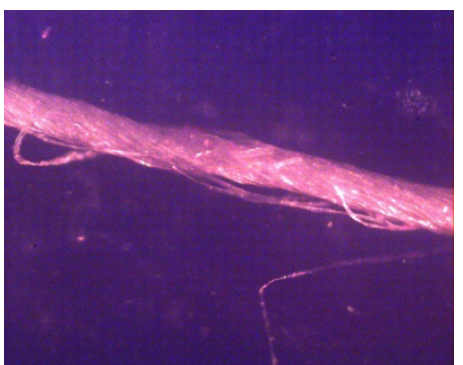

Figure 6: System R (0.9 Ne/ 50 $\mathrm{Ne})$. can be considered as an important finding from the perspective of the comfort properties of fabrics as the yarn produced has softer surface and higher lustre value as a result of the short hairs. Whereas, the System D showed a drastic reduction in hairiness (S3 Value) as a result of the higher suction length. Owing to the least 'S3 Value' the System $D$ yarn exhibited better performance in terms of abrasion resistance.

Yarn lustre: Yarn lustre is the ability of the yarn to reflect the light from its surface. There are various factors which decide the yarn lustre. The following Figure 5 shows the different trends of yarn lustre of different yarn samples.

The lustre property can be seen to correlate with the short hairs and inversely proportional to the yarn density, as the yarn density increases the lustre or reflectance value goes on reducing due to the increase in roundness of the yarn. No difference with the change in feed hank.

\section{Stereo microscopic images (75x magnifications)}

As seen in the images, a peculiarity of the System $\mathrm{R}$ yarns can be observed. There are fibres that protrude out on the surface but the other end of the fibres is bound in the yarn body which may be termed as looped hairs, these don't protrude out completely from the yarn and so during the testing, this may have been accounted as the short hairs i.e. less than $3 \mathrm{~mm}$ hairs. This inference is supported by the higher

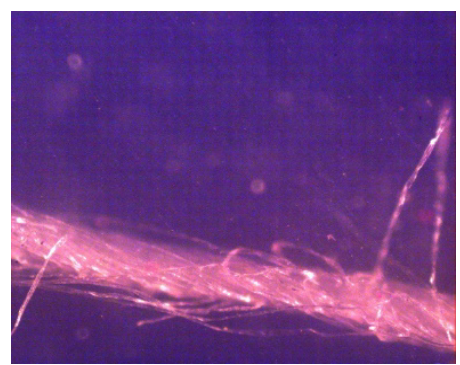

Figure 7: System R (1.1 Ne/ 50s $\mathrm{Ne})$.

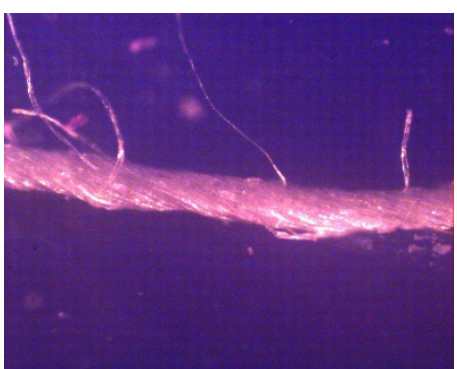

Figure 8: System $\mathrm{S}\left(0.9 \mathrm{Ne} / 50^{\mathrm{s}} \mathrm{Ne}\right)$.

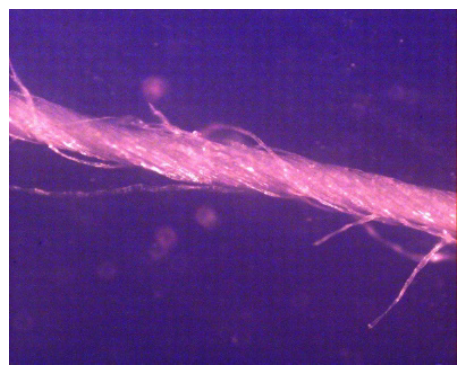

Figure 9: System S (1.1 Ne/ 50 $\mathrm{Ne})$. 


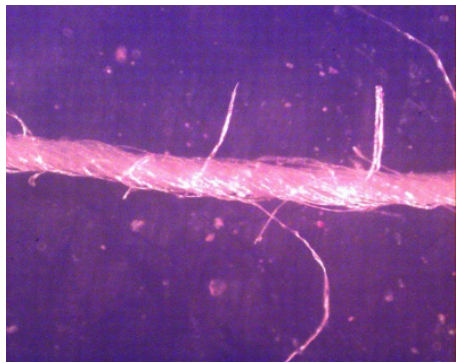

Figure 10: System D $\left(0.9 \mathrm{Ne} / 50^{\mathrm{s}} \mathrm{Ne}\right)$.

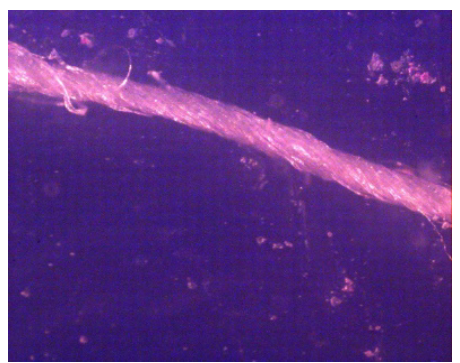

Figure 11: System $D\left(1.1 \mathrm{Ne} / 50^{\mathrm{s}} \mathrm{Ne}\right)$.

number of short hairs observed for system R. These fibres make the yarn smoother and are also may be responsible for higher lustre as they project more reflecting surfaces for the incident light (Figures 6-11).

The System S and System D yarns follow the normal helical yarn twisting pattern; it can also be observed that the yarns on the System D show highest packing density. Due to fine diameter and high density the System $D$ yarn, it can be predicted that it would give better process ability \& a clearer structure. The microscopic images make it very clear that the surface integrity of System R yarn is peculiar and the high lustre and lesser friction exhibited by the yarn maybe a result of the looped hairs observed in the yarn.

\section{Conclusion}

It can therefore be concluded that the yarn spun on System D system can be considered very attractive from the perspective of least hairiness, but the yarns manufactured on other systems dominate the surface characteristics in their own peculiar way.
The System R yarn has highest number of short hairs and a peculiar bulky structure with looped hairs on the surface despite the yarn satisfying all the characteristics of a compact yarn. The yarn possess highest lustre value and least friction, therefore the yarn can be said to dominate in terms of comfort, as it contributes to both physiological comfort and aesthetic comfort. The system $S$ yarn possesses higher evenness, which is a desirable factor from the commercial perspective. A constructive conclusion drawn out of the study on effect of feed hank is that there is no significant difference of feed hank on yarn properties and hence we can go for coarser roving hank i.e. $(0.9 \mathrm{Ne})$ and thus achieve higher productivity at roving frame.

\section{References}

1. Gupta BS (2008) Friction in textile materials, Wood head publishing pp: $377-$ 378.

2. Singh MK, Nigam A (2013) Effect of Various Ring Yarns on Fabric Comfort. J Ind Eng.

3. Ozdil N, Ozdoğan E, Demirel A, Oktem T (2005) Understanding and Improving the Durability of Textiles Fibres Text East Eur 13: 50

4. Cheng KPS, Yu C (2003) A Study of Compact Spun Yarns. Text Res J 73 : 345-349.

5. Beceren Y, Nergis BU (2008) Comparison of the Effects of Cotton Yarns Produced by New, Modified and Conventional Spinning Systems on Yarn and Knitted Fabric Performance. Text Res J 78: 297-303.

6. Genesan S, Venkatachalam A, Subramaniam V (2007) Fibre migration in compact spun yarns: Part II - Mechanical compact yarn. Indian J Fiber Text Res 32: 169-172.

7. Basu A (2009) Yarn structure-properties relationship. Indian J Fiber Text Res 34: 287-294.

8. El-Sayed MAM, Sanad SH (2010) In Compact spinning Technology, Advances in Yarn Spinning Technology. Wood head Publishing Series in Textiles pp: 237260

9. Ganesan S, Ramakrishnan G (2006) Fibre migration in compact-spun yarns Part I-Pneumatic compact yarn. Indian J Fibre Text Res 31: 381-386.

10. Goyal A, Mishra P, Chutani A (2007) Comparative study of ring and compact spun yarns. Melliand Int 13: 102-106

11. Kane CD, Patil UJ, Jawale SN, Patil ST (2010) Compact and conventional ring spun blend yarns and carbonizing effect. Melliand Int 16: 152.

12. Jackowski T, Cyniak D, Czekalski J (2004) Compact Cotton Yarn. Fibres Text East Eur 12: 44.

13. Basal G, Oxenham W (2006) Comparison of Properties and Structures of Compact and Conventional Spun Yarns. Text Res J 76: 567-575. 